\title{
Study on the Microgrid Pluripotent Complementary and Comprehensive Economic Optimization Planning Based on Virtual Energy Theory
}

\author{
Peng Zhang ${ }^{1,2}$, $\mathrm{Na} \mathrm{Liu}^{2}$, Bo-yang Qu ${ }^{1}$, Jun-ming Xiao ${ }^{1}$, and Man-man Lin ${ }^{1}$ \\ ${ }^{1}$ Zhongyuan University of Technology, Zhengzhou, 450007, China \\ ${ }^{2} \mathrm{HaMi}$ Technical College, HaMi 100875, China
}

\begin{abstract}
In this paper, a comprehensive economic allocation method based on virtual energy theory for microgrid complementary power supply is proposed, which is successfully applied to the multi energy complementary planning and comprehensive economic planning of an island microgrid. In order to evaluate and optimize the microgrid in the planning stage more objectively based on the characteristics of various combinations of renewable micro generation and flexible operation modes, a new method of the micro-grid comprehensive economic configuration and optimization of the distributed generation is proposed based on virtual energy theory. Firstly, the Micro-grid model structure based on the virtual energy theory is given. Secondly, the virtual energy conversion model of different distributed power generations is also studied. The micro-grid pluripotent complementary and comprehensive economic optimization model (PCCEP) based on virtual energy theory are reached too. Combined with a practical example, a PCCEP method of the micro-grid based on the Homer software platform is discussed. The case study indicates that the method can avoid the uncertainty of the decision-making factors and the subjectivity of expert evaluation. It is shown that the new method is a practical solution for microgrid comprehensive economic optimization planning.
\end{abstract}

\section{Introduction}

Micro grid [1], [2], [3] is a small power distribution system consisting of distributed power supply device, energy storing device, energy conversion device, load, protection and monitoring device, etc. Micro grid has become an effective form of renewable energy utilization and has great application prospects [4], [5]. Because the characteristics of distributed power supply vary greatly, the multi-energy complementation, comprehensive economic allocation and evaluation of the micro-grid has become a technical problem to be solved urgently. In this paper, a comprehensive economic allocation method based on virtual energy theory for microgrid complementary power supply is proposed. And the new method has been successfully applied to the multi energy complementary planning and comprehensive economic planning of an island micro grid.

The remainder of this paper is organized as follows. In the next section, we propose and study the transformation model of distributed generation based on virtual energy theory. The comprehensive economic planning of microgrid based on virtual energy theory is introduced in detail. Section IV reports the simulation and analysis of an example. The conclusions drawn from this paper are given in Section V.

\section{TRANSFORMATION model of distributed generation based on virtual energy theory}

The microgrid structure scheme based on the virtual energy theory is shown in Fig.1. The power generation and storage process of distributed generation requires corresponding power control devices [1], [6]. The cost efficiency factor $(\zeta)$ of the distributed generation is constructed according to the power generation and storage characteristics. The conversion model of power generation from PV, wind power generation and Diesel engine power generation to virtual energy pool can be established. The volume conversion formula of distributed generation (such as wind energy, photovoltaic, gas turbine power generation, etc.) into virtual energy pool is put forward. Using these formulas and models, the transformation and comprehensive evaluation model from the distributed generation to virtual energy pool is put forward, which can be used for the comprehensive evaluation of energy efficiency of distributed generation in micro grid. By optimizing the volume of the total virtual energy pool, the multi energy complementary optimization of microgrid can be realized. This model can solve the problem of lacking 


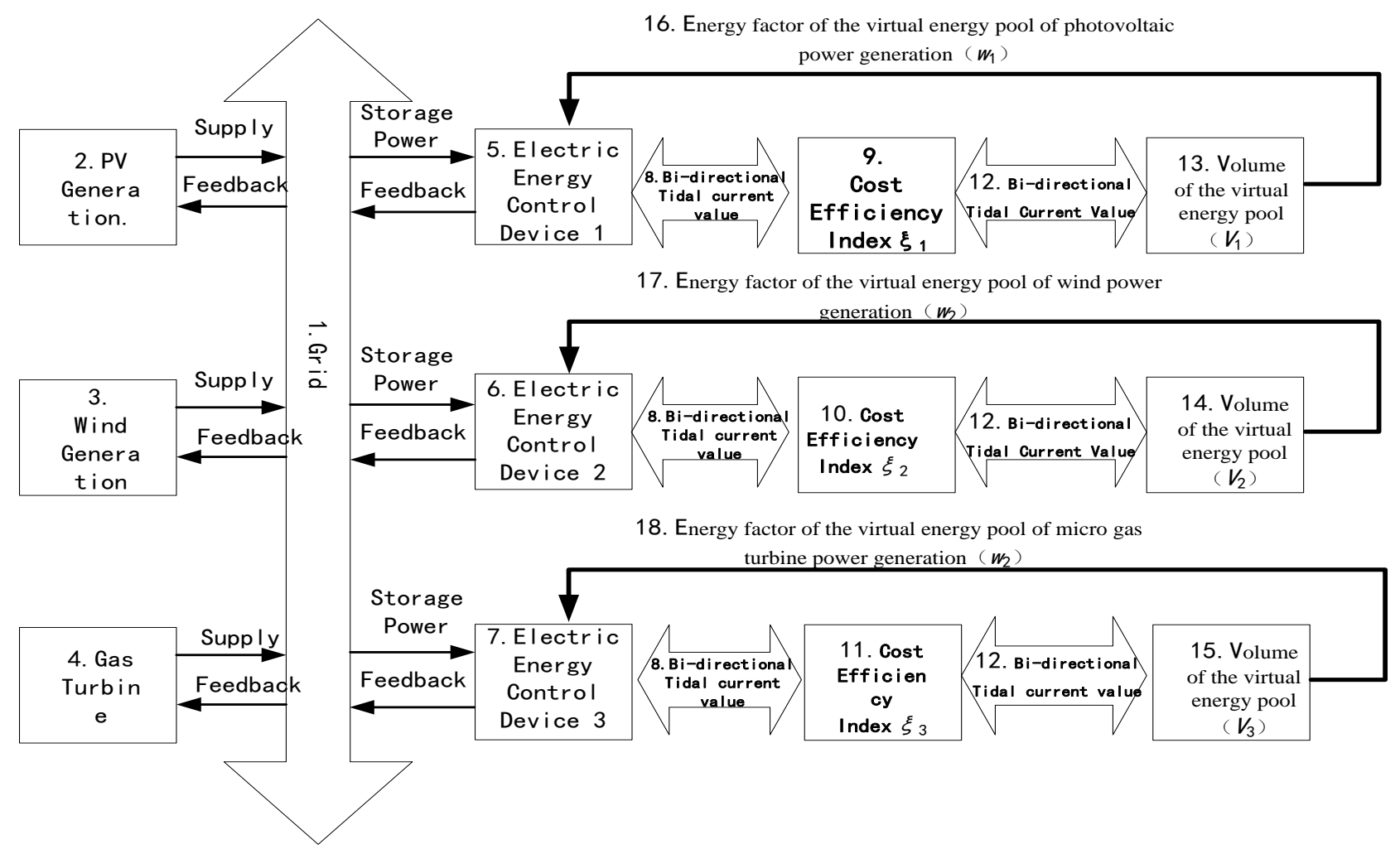

Fig. 1. Schematic diagram of Micro grid model based on virtual energy pool.

effective evaluation and management model in microgrid planning.

\subsection{Conversion formula from distributed generation to virtual energy}

First point: Conversion formula from photovoltaic power to virtual energy. Referring to the model in Fig. 1, the conversion formula from Photovoltaic array power generation to the virtual energy pool can be constructed. The concrete form is shown in Formula (1).

$$
V_{1}=\frac{1}{9.8 H_{1} \rho_{1}} \zeta_{1} \sum\left[\int \eta S I(1-0.005)\left(t_{0}+25\right) d t\right]
$$

Where, $V_{1}$ is the volume of the virtual energy pool based on the secondary battery conversion relationship, and the unit is $\left(\mathrm{m}^{3}\right), H_{1}$ is the virtual height of virtual energy pool, and the unit is $(\mathrm{m}), \rho_{1}$ is the density of virtual energy storage liquid of virtual energy pool, $\zeta_{1}$ is the cost efficiency factor of power conversion in virtual energy pool, $\int \eta S I(1-0.005)\left(t_{0}+25\right) d t$ is the total power generation of photovoltaic array, $\eta$ is the efficiency of photovoltaic cells, $S$ is the total area of PV array, $I$ is the intensity of irradiation for the sun, and $t_{0}$ is the atmospheric temperature around PV array.

Second point: Conversion formula from wind power to virtual energy. Referring to the model in Fig. 1, the conversion formula from wind power generation to the virtual energy pool can be constructed. The concrete form is shown in Formula (2).

$$
V_{2}=\frac{1}{9.8 H_{2} \rho_{2}} \zeta_{2} \sum_{i=0}^{M} \int \frac{1}{2} C_{p} A \rho_{\omega} V^{3} d t
$$

Where, the meaning of $V_{2}, H_{2}, \quad \zeta_{2}$ is the same as those in formula (1), $\sum_{i=0}^{M} \int \frac{1}{2} C_{p} \rho_{\omega} V^{3} d t$ is the total power generation of wind power generation, $C_{p}$ is the efficiency of the Wind turbine generation, $A$ is the effective page area of the fan, $\rho_{\omega}$ is the air density, and $V$ is the wind speed.

Third point: Conversion formula from gas turbine power generation to virtual energy. Referring to the model in Fig. 1, the conversion formula from gas turbine power generation to the virtual energy pool can be constructed. The concrete form is shown in Formula (3).

$$
V_{3}=\frac{1}{9.8 H_{3} \rho_{3}} \zeta_{3} \sum_{j=0}^{N} \eta_{r} m t_{g}
$$

Where, the meaning of $V_{3}, H_{3}, \rho_{3}, \quad \zeta_{3}$ is the same as those in formula (1), $\sum_{j=0}^{N} \eta_{r} m t_{g}$ is the total power generation of distributed micro gas turbine power generation, $\eta_{r}$ is the generation efficiency of distributed micro gas turbine, $m$ is the fuel quality, and $t_{g}$ is the calorific value of unit fuel combustion.

Fourth point: Conversion formula from other forms of distributed energy generation to virtual energy. 
Referring to the model in Fig. 1, the conversion formula from other forms of distributed energy generation to the virtual energy pool can be constructed. The total power consumption of the other types of distributed power generation devices that flow through the power control devices is $W_{x}=\int P d t$. The conversion formula from other forms of distributed energy generation to the virtual energy pool is shown in formula (3).

$$
V_{x}=\zeta_{x} \frac{W_{x}}{9.8 H_{x} \rho_{x}}
$$

Where, the meaning of $V_{x}, H_{x}, \rho_{x}, \zeta_{x}$ is the same as those in formula (1).

\subsection{Distributed microgrid generation model based on virtual energy theory}

After calculating the volume of the virtual energy pool corresponding to the distributed power generation, the total capacity of the virtual power pool corresponding to the whole micro grid power generation can be calculated according to formula (5).

$$
V=V_{1}+V_{2}+V_{3}+\cdots+V_{\mathrm{x}}+\cdots
$$

The total capacity of the virtual energy pool corresponding to the microgrid is determined by the type, quantity and power generation of the distributed generation mode used in the system. And the total capacity of virtual energy pool and the capacity of each virtual energy pool are normalized. Then, the per-unit total capacity of virtual energy pool can be determined with the formula (6).

$$
1=\frac{1}{9.8 H}\left(\lambda_{1}+\lambda_{2}+\lambda_{3}+\cdots+\lambda_{x}+\cdots\right)
$$

The nominal energy capacity of the rated energy in the microgrid virtual energy pool can be shown in formula (6).

$$
1=w_{1}+w_{2}+w_{3}+\cdots+w_{x}+\cdots
$$

Where, $\lambda_{1}=\zeta_{1} \frac{\sum\left[\int \eta \operatorname{SI}(I-0.005)\left(t_{0}+25\right) d t\right]}{V}$ is the capacity factor of the virtual energy pool of photovoltaic power generation. $w_{1}=\frac{\lambda_{1}}{9.8 \mathrm{H}}$ is the energy factor of the virtual energy pool of photovoltaic power generation. $\lambda_{2}=\zeta_{2} \frac{\sum_{\mathrm{i}=0}^{M} \int \frac{1}{2} C_{p} A \rho_{\omega} V^{3} d t}{V}$ is the capacity factor of virtual energy pool of wind power generation. $w_{2}=\frac{\lambda_{2}}{9.8 \mathrm{H}}$ is the energy factor of virtual energy pool of wind power generation. $\lambda_{3}=\zeta_{3} \frac{\sum_{\mathrm{j}=0}^{\mathrm{N}} \eta_{7} m t_{g}}{V}$ is the capacity factor of virtual energy pool for micro gas turbine power generation. $w_{3}=\frac{\lambda_{3}}{9.8 \mathrm{H}}$ is the energy factor of virtual energy pool for micro gas turbine power generation. $\lambda_{7}=\zeta_{7} \frac{W_{7}}{V}$ is the capacity factor of the virtual energy pool of other types of distributed generation. $w_{7}=\frac{\lambda_{7}}{9.8 \mathrm{H}}$ is the energy factor of the virtual energy pool of other types of distributed generation. In the actual operation of microgrid, $\sum w_{j}^{\prime}$ is the storage virtual energy total capacity of the micro-grid virtual energy pool. $\sum w_{j}^{\prime}$ satisfies the following conditions: $0 \leq \sum w_{j}^{\prime} \leq 1$, $j=1,2,3,4,5,6, \cdots X \cdots$. And the per-unit virtual energy of each virtual energy pool should satisfy the formula (8).

$$
0 \leq \sum w_{j}^{\prime} \leq w_{j}, \quad j=1,2,3,4,5,6, \cdots X \cdots
$$

\subsection{Economic benefit calculation of distributed generation based on virtual energy}

Micro grid consists of photovoltaic, wind power, diesel power generation, water power, various energy storage and other forms of energy [7], [8], [9]. The distributed generation can build the micro grid under certain resource input. Based on the model in the previous chapters, the micro grid of the virtual energy pool can be evaluated economically [10]. Thus, the comprehensive economic evaluation of distributed generation can be realized. During the operation period of the micro grid, all kinds of distributed generation equipment with negative economic benefit coefficient are put into operation, and the corresponding energy resources $(F)$ are put into operation too. Considering the environment, pollution and other factors, the corresponding energy resources can have positive or negative economic benefit coefficient [11], [12]. the corresponding energy resources $(\mathrm{F})$ is sent to the distributed generation equipment respectively and convert to virtual energy [13], [14]. So, the comprehensive energy efficiency characteristics of microgrid based on virtual energy can be expressed as the relationship between $\mathrm{F}$ and $\mathrm{V}$ in microgrid operation. If $\mathrm{F}$ is input and $\mathrm{V}$ is output, it can be called the comprehensive benefit input output characteristic of microgrid system.

First point: Comprehensive benefit characteristics of micro grid generation unit. The relationship between the economic benefits $(F)$ and virtual energy $(V)$ is extremely complex. In general, $F$ is not only a function of $V$, but also related to the changing factors of $V$. This paper only discusses the static relation of $F$ as input and $V$ as output. And the comprehensive benefit characteristics of microgrid generation can be expressed as:

$$
F=F(V)
$$

Where, $V$ is the virtual power output of microgrid power generation, the unit is $\mathrm{m}^{3} . F$ is the comprehensive benefit cost of the distributed generation of microgrid, which can be calculated with the economic cost per hour (the cost is related to the market factors). It is an efficient way to measure the cost of consumption by consuming 
economic costs, which is widely used in the economic field to measure the operating efficiency of the system [15], [16]. In fact, if the cost of the actual economic benefits generated by the distributed generation unit is used to measure the input cost, the cost of economic benefits will be more effectively reflected, and this method will be more reasonable, which will be discussed in detail in another paper.

Second point: The comprehensive benefit factor of microgrid generation unit. The cost efficiency factor [17] described in the preceding section is a multivariable function, and its expression is,

$$
\zeta_{j}=f\left(F_{1 j}, F_{2 j}, \eta_{j}, E_{j}, S_{j}, O_{p j}, K_{j}, G_{j}, L_{j}\right) \text {,Where, }
$$
$j=1,2,3,4,5,6, \cdots X \cdots, F_{1 j}$ is the investment cost of distributed generation equipment, $F_{2 j}$ is the operation $\&$ maintenance cost of the distributed generation unit and the cost of fuel consumption, $\eta_{j}$ is the operation efficiency index of the distributed generation equipment, $E_{j}$ is the environmental protection cost of distributed generation equipment, $S_{j}$ is the social benefit cost of distributed generation equipment, $O_{p j}$ is the optimization factor of distributed generation equipment, $K_{j}$ is the reliability index of distributed generation equipment, $G_{j}$ is the government support index for energy storage devices, and $L_{j}$ is the annual utilization index of energy storage device. A static calculation method of partial benefit index is given below.

1) Energy saving benefit calculation. The energysaving benefits of microgrid include two aspects: bThe value of fossil energy saved by renewable energy power generation. 2 The value of heat and cold energy provided by the waste heat generated by the waste heat of the micro gas turbine under the mode of cooling, heat and power cogeneration. Taking the gas turbine as an example, the energy saving efficiency is calculated by:

$$
B_{\mathrm{ES}}(x)=\sum_{I=1}^{N} k_{\text {coal }} p_{\text {coal }} E_{i} x_{i}+\frac{E_{3} \varepsilon x_{3}}{1-\eta}\left(k_{h e} p_{h e}+k_{c o} p_{c o}\right)
$$

Where, $k_{\text {coal }}$ is the average coal consumption of power generation unit for thermal power unit and the value is $357 \mathrm{~g} / \mathrm{kwh}, P_{\text {coal }}$ is Unit price for coal and the value is $700 Y / \mathrm{t}, E_{i}$ is the annual power generation for Type I distributed generation, $E_{3}, x_{3}$ are the annual generating capacity and installation number of micro gas turbine (i=3) respectively, $p_{h e}, p_{c o}$ are thermal energy price and cold energy price respectively and the prices are 51.4 $¥ / \mathrm{GJ}$ and $79.6 ¥ / \mathrm{GJ}$.

2)Environmental benefit calculation. The mitigation benefits of micro grids can be measured by the environmental benefits of the same amount of electricity produced by the microgrid [15],[18], and the environmental benefits are generally represented by the amount of pollutants such as $\mathrm{SO}_{2}, \mathrm{NOx}, \mathrm{CO}_{2}, \mathrm{CO}$ and fly ash which are less discharged by distributed renewable energy power generation than that by the traditional coal-fired power generation. The calculation formula of environmental benefit is:

$$
B_{E R}(x)=\sum_{i=1}^{N} \sum_{j=1}^{M} V_{j}\left(\delta_{c, j}-\delta_{i, j}\right) E_{e, i} x_{i}
$$

Where, $V_{j}$ is the environmental value of item $\mathrm{j}$ pollutants, $\mathrm{M}$ is the type of pollutant, $\delta_{c, j}$ is the quantity of $j$ pollutant discharged by coal fired unit producing a certain amount of electric energy, $\delta_{i, j}$ is the number of $j$ pollutants emitted by $i$ power generation units producing a certain amount of electric energy, $j=1 \sim 5$ represents $\mathrm{SO}_{2}, \mathrm{NOx}, \mathrm{CO}_{2}, \mathrm{CO}$ and ash, respectively.

3) Reliability benefit calculation. When the power grid fails, the microgrid can run autonomously to ensure the power supply to the local load, which will improve the reliability of the power supply [19], [20]. Microgrid can improve power supply reliability and reduce power outage. Power outage will bring huge economic losses. The reliability benefit of microgrid is the reduced economic losses caused by microgrid. The formula for calculating reliability benefit is formula (12).

$$
B_{R B}(x)=I_{E A R}\left[\sum_{k \in Q} \lambda_{k}\left(r_{k}-P_{M} T_{R}\right) P_{L}-\left(1-P_{M}\right) P_{I S O} \sum_{t=1}^{8760} E_{L S P, t}(x)\right]
$$

Where, $I_{E A R}$ is the outage loss evaluation rate, And it is used to describe the economic loss of a class or whole society user who loses $1 \mathrm{kwh}$ every power outage, $I_{E A R}$ takes $50 ¥ / \mathrm{kwh}, \lambda_{k}, r_{k}$ are the average annual outage rate and annual average outage time of load point $\mathrm{k}$ when microgrid is connected to grid, $\lambda_{k}, r_{k}$ were 0.408 times / year and $9.22 \mathrm{~h} /$ years, $P_{L}$ is the average load within the microgrid, $P_{M}$ is the islanding failure rate for microgrid, $P_{M}$ takes $0.3, T_{R}$ is the restart time for microgrid power supply, $P_{I S O}$ is the annual islanding probability of microgrid, $E_{L S P, \mathrm{t}}$ is the power shortage of $t \mathrm{~h}$ in islanding operation of microgrid.

\section{Comprehensive economic planning of microgrid based on virtual energy theory}

The economic optimization of the micro grid distributed generation is to allocate the active power of power generation to the power generation units of the micro grid, making the total operating cost of the micro grid the lowest and the economic benefit the highest. There are two kinds of integrated economic planning methods in microgrid with multiple distributed generation systems. (1) The basic load benefit method, First, the distribution power generation is arranged according to the operating efficiency of a running point (such as the highest economic benefit operation point). Then, the 
load is added to the distributed generation with high benefit, and then the analogy is made. (2) The optimal point load method, first, the distributed generation is queuing according to the optimal economic benefits. Then, the distributed generation is allocated to the optimal operating point rather than the full load of a single distributed generation. The two methods are only based on a single factor to optimize the allocation of distributed generation, So, the comprehensive economy and benefit of microgrid cannot be accurately evaluated with those methods. In the next section, a comprehensive economic planning method for microgrid based on virtual energy theory is studied.

\subsection{Objective function}

In this paper, the comprehensive economic planning method of microgrid power is described as follows: By using of virtual energy pool theory, the cost, limit capacity and load characteristics of various alternative distributed power sources need to be referred and further studied. The wind, solar radiation, diesel and load are used as input data. The maximum net benefit of microgrid is the optimization objective. Considering the reliability of microgrid, the adequacy of islanding operation and the environmental constraints such as carbon emissions, the installation number of various alternative power sources is optimized. The objective function of the comprehensive benefit factor is as follows.

$$
\max _{\text {NET }}(x)=\sum_{i=1}^{n} F_{i}\left(P_{i}\right)=\sum_{i=1}^{n}\left(B_{\text {Total }}\left(P_{i}\right)-C_{\text {Total }}\left(P_{i}\right)\right)
$$

$B_{\text {Total }}\left(P_{i}\right), C_{\text {Total }}\left(P_{i}\right)$ are the comprehensive benefits and comprehensive costs of the $i$ power configuration in microgrid.

First point: Comprehensive cost calculation. Integrated with the investment cost, operation and maintenance cost and fuel cost of distributed generation, the annual comprehensive cost calculation model of microgrid power supply configuration can be obtained.

$$
B_{\text {Total }}\left(P_{i}\right)=\sum_{i=1}^{N} \lambda_{i}\left[C_{V N, i} \frac{r(1+r)^{Y_{i}}}{(1+r)^{Y_{i}}-1}+C_{O M, j} P_{i}+C_{F U, i} E_{i}\right] x_{i}
$$

Where, $\quad C_{I V, i} \frac{r(1+r)^{Y_{i}}}{(1+r)^{Y_{i}}-1}$ is the average annual installed cost of power supply, $C_{O M, j} P_{i}$ is the annual average operation and maintenance cost of power supply which is proportional to the installed capacity of the unit $P_{i}, C_{F U, i} E_{i}$ is the average annual fuel cost for power generation. $C_{I V, i}, C_{O M, j}$ and $C_{F U, i}$ are the installed cost, annual operation and maintenance cost, and fuel cost of the $i$ distributed generation, which should Considers the impact of environmental factors and government policies. $Y_{i}$ is the life cycle period of the $i$ distributed power generation, and in this article, the value of $Y_{i}$ all is 25 years. $E_{i}$ is the annual power output for the $i$ distributed generation. $\mathrm{A}$ is the discount rate, and the value is $6 \%$ in this paper. $\lambda_{i}$ is the cost correction factor, which is related to the environmental protection intensity, technical maturity and government support of the type $i$ distributed generation. The correction coefficients of PV and wind energy ranges from 0.5 to 0.8 . The correction coefficient of diesel power generation ranges from 1.0 to 1.5. The correction coefficient of hydraulic generator ranges from 0.7 to 0.8 . The correction coefficient of thermal power generation ranges from 1.2 to 1.5 .

Second point: Comprehensive benefits of distributed generation. This part calculates the energy saving benefits, emission reduction benefits, loss reduction benefits and reliability benefits of distributed generation and Microgrid respectively. The summation of the four benefits can obtain the comprehensive benefits of microgrid power generation configuration. The concrete formula is:

$$
B_{\text {Total }}\left(P_{i}\right)=B_{\mathrm{ES}}\left(P_{i}\right)+B_{E R}\left(P_{i}\right)+B_{R B}\left(P_{i}\right)
$$

Where, $B_{\text {Total }}\left(P_{i}\right)$ is the annual comprehensive benefit of microgrid power supply configuration, $B_{\mathrm{ES}}\left(P_{i}\right), B_{E R}\left(P_{i}\right)$ and $B_{R B}\left(P_{i}\right)$ are energy saving benefits, emission reduction benefits and reliability benefits of microgrid power configuration.

\subsection{Constraint conditions}

First point: Calculation constraint of wind, light and micro gas turbine.

$$
\left\{\begin{array}{l}
P_{W T} \leq N_{W T} \cdot P_{W T N} \leq P_{W T \max } \\
P_{P V} \leq N_{P V} \cdot P_{P V N} \leq P_{P V \max } \\
P_{O X} \leq N_{O X} \cdot P_{O X N} \leq P_{O X \max }
\end{array}\right.
$$

Where, $N_{W T}, N_{P V}, N_{O X}$ are the number of wind, photovoltaic and gas turbine, $P_{W T N}, P_{P V N}, P_{O X N}$ are the single rated capacity of wind turbine, PV and gas turbine, $P_{W T \max }, P_{P V \max }, P_{O X \max }$ are the upper limit of available resources for wind, photovoltaic and gas turbines.

Second point: Calculation constraint of battery charging and discharging. Excessive battery charge and discharge rate will reduce the service life of the battery. So, the charge and discharge capacity of the battery cannot exceed $20 \%$ of its available capacity per hour. At a certain $\mathrm{t}$ time point, when the sum of the generated energy of the fan and the PV array is greater than the load, the battery pack is charged. The battery constraint satisfies the following formula.

$$
\left\{\begin{array}{c}
E_{W P, t} \eta_{i n v}-E_{L, t}>0 \\
\Delta E_{t}^{+} \leq 0.2 E_{B, t-1}
\end{array}\right.
$$


Otherwise, battery discharges, then

$$
\left\{\begin{array}{c}
E_{W P, t} \eta_{i n v}-E_{L, t}<0 \\
\Delta E_{t}^{-} \leq 0.2 E_{B, t-1}
\end{array}\right.
$$

Where, $\Delta E_{t}^{+}$and $\Delta E_{t}^{-}$are the charging and discharging capacity of battery in th time point.

Third point: Calculation constraint of power supply reliability for islanding operation of microgrid. Loss of load probability ( LOLP) is a common index to characterize the reliability of microgrid system, and its magnitude is the ratio of the load demand when the system cannot meet to the total load demand. In order to ensure the generation adequacy of islanding operation of microgrid, LOLP should satisfy the following formula.

$$
R_{L P S P} \leq R_{\max }
$$

And

$$
\begin{gathered}
E_{L S P, \mathrm{t}}=\left\{\begin{array}{c}
E_{L, t}-E_{\text {Total }, t}, E_{\text {Total }, t}-E_{L, t} \leq 0 \\
0, E_{\text {Total }, t}-E_{L, t} \succ 0
\end{array}\right. \\
E_{\text {Total }, t}=E_{W P, t}+E_{M T, t}+d E_{t}
\end{gathered}
$$

Where, $R_{\max }$ is the maximum allowable outage probability of microgrid running throughout the year, $E_{\text {Total }, t}$ is the total power output for the microgrid in $\mathrm{t}$ hours, $d E_{t}$ is the discharge capacity of battery in thours, When the battery is charged, the value is 0 .

Fourth point: Calculation constraint of pollutant emission. With the global warming, the study of reducing emissions $\left(\mathrm{CO}_{2}, \mathrm{CO}, \mathrm{SO}_{2}, \mathrm{PM}\right.$ particles, hydrogen and oxygen compounds, nitrogen oxides, etc.) and development of green environmental protection economy has become the current research hot spot. In this paper, the pollutant emission constraint is added to the microgrid power optimization allocation model to evaluate and limit the pollutant emission of micro grid power generation. Pollutants will be directly or indirectly discharged from fans, photovoltaic arrays, micro gas turbines, and battery power generation, the constraint conditions of micro grid pollutant emission can be described as follows:

$$
\sum_{i=1}^{n} \sum_{j=1}^{m} E_{i} P_{i} \delta_{i, j} \leq e_{\max }
$$

Where, $e_{\max }$ is the maximum allowable value of annual pollutant discharge for microgrid. The connection of distributed power will affect the node voltage and line current in microgrid. In this paper, the influence of node voltage constraint and line current constraint is considered.

\subsection{Economical optimal allocation method of microgrid distributed generation}

Genetic algorithm is a random search optimization algorithm simulating biological evolution. It has strong robustness and adaptability and has been applied to study the power system planning problems. In this paper, an adaptive genetic algorithm based on binary encoding is put forward. Each component of the chromosome is the number of distributed generators in the microgrid. And the binary coding length of each component depends on the single machine capacity of distributed generation corresponding to the component, the peak load demand within the microgrid and the encoding accuracy. Based on the improved genetic operator method proposed by the literature [16] and Taguchi algorithm, the crossover operation is optimized, which will improve the convergence and global performance of the algorithm.

Considering the influence of the constraints, the penalty function is constructed to transform the constrained problem into the unconstrained problem in this paper. Photovoltaic, wind, micro gas turbines and other power generation constraints have been discussed in the microgrid configuration optimization model based on the virtual energy theory. Other constraints are contained in the fitness function in the form of penalty function.

$$
\begin{gathered}
F(P)=F_{N E T}(P)-\sum_{i=1}^{M} \lambda_{p}\left(\alpha_{i}\right) \\
\lambda_{p}\left(\alpha_{i}\right)=\left\{\begin{array}{c}
0, \alpha_{i \min } \leq \alpha_{i} \leq \alpha_{i \max } \\
\lambda_{i}, \text { else }
\end{array}\right.
\end{gathered}
$$

Where, $M$ is the number of constraints, $\lambda_{p}\left(\alpha_{i}\right)$ is the i constraint penalty item, $\alpha_{i}$ is the corresponding penalty factor, and it is a larger positive number.

\section{Simulation and analysis of an example}

In this section, an example of optimal allocation of distributed generation in island microgrid is given to verify new method of microgrid pluripotent complementary and comprehensive economic optimization planning based on virtual energy theory. This island (Xiachuan island) is in Guangdong province of China. The photovoltaic, diesel generator, wind power, and tidal energy of the island are very rich. The island power supply system connects with land power grid through submarine cable. Submarine cables have a maintenance period of 3 months a year. The island power demand is stable. Based on the above constraints, the specific experimental process is as follows.

\subsection{Island load forecasting}

Annual load of Xiachuan Island is basically consistent, and the annual power supply and electricity sales are basically consistent too. According to the electric load from 2010 to 2014, the electrical load of 2015 year can be obtained based on the artificial neural network method, as shown in Figure 2(unit: kwh). It can be shown that September is the peak period of annual electricity consumption, and January is the troughs 
period of annual electricity consumption.

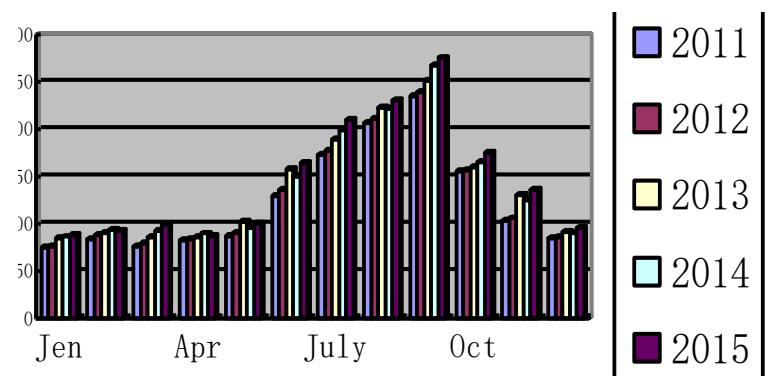

Fig. 2. Electricity demand forecast of the Island.

Annual load of Xiachuan Island is basically consistent, and the annual power supply and electricity sales are basically consistent too. According to the electric load from 2010 to 2014, the electrical load of 2015 year can be obtained based on the artificial neural network method, as shown in Figure 2(unit: kwh). It can be shown that September is the peak period of annual electricity consumption, and January is the troughs period of annual electricity consumption.

The island load is mainly based on Residents' electricity and commercial electricity. Daily load curve of typical household electricity consumption is selected as the daily load curve of electricity consumption in Xiachuan Island in this paper. The largest power load in September and the minimum electricity consumption in January from 2010 to 2014 were analyzed. The daily load curve of January and September can be predicted based on support vector machine algorithm, as shown in Figure 3.

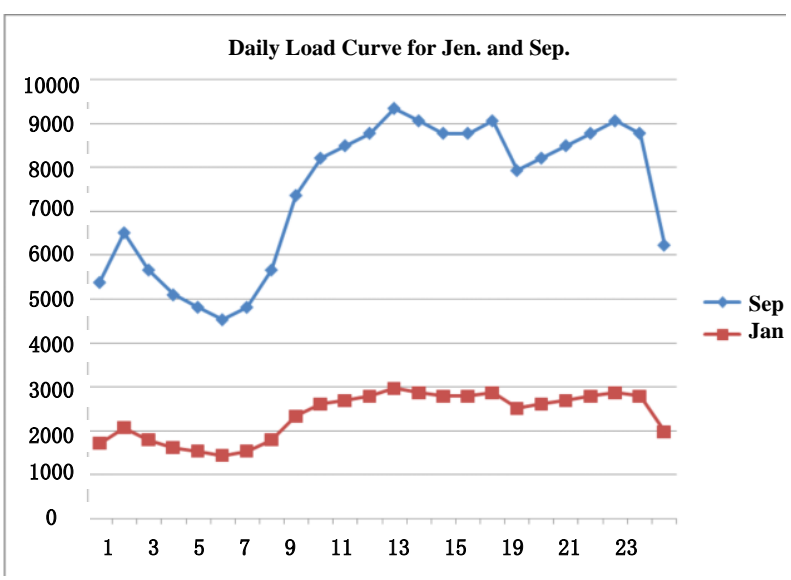

Fig. 3. Daily load curve of the Island.

According to the analysis of the load data in Figure 3, the maximum daily load is about 10 megawatts, while in January it is only about 3 megawatts. The load has great seasonal and temporal characteristics.

\subsection{Model constraint}

First point: Wind power generation constraints. The annual average wind speed in Xiachuan Island is up to $4.85 \mathrm{~m} / \mathrm{s}$. The annual effective wind speed time length can reach more than $60 \%$ of the total wind speed time. The effective wind energy value varies greatly in each month, the high value period is from October to
February next year, and the low value period is from April to August. Daily power generation peak is 21:30 to $6: 30$, power generation trough at $9: 30$ to $15: 30$, as shown in figure 4.

Second point: Photovoltaic power generation constraints. The annual sunshine hours in Xiachuan Island can reach about 2006 hours, and the annual solar radiation energy reached $137.2 \mathrm{kwh} / \mathrm{m}^{2}$. The annual solar radiation is the smallest in February, the largest in July. The shortest average sunshine duration is from early February to mid-April. The average daily sunshine is only 3.3 hours. The longest average sunshine duration is in July. The average daily sunshine is only7.6 hours, as shown in Fig. 5.

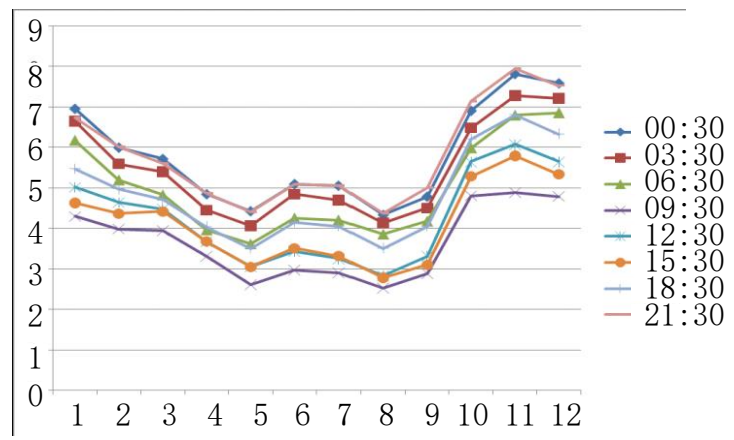

Fig. 4. Daily average wind conditions of the Island $(\mathrm{m} / \mathrm{s})$

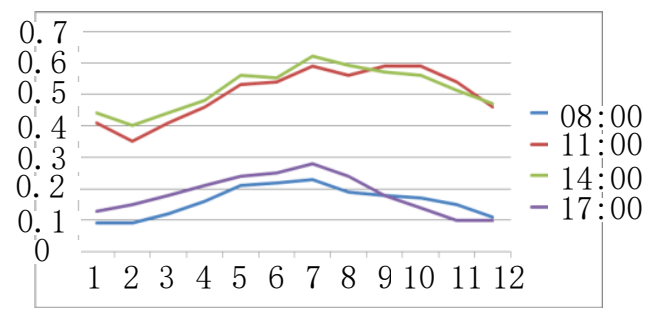

Fig. 5. Average daily light intensity distribution.

Third point: Other boundary conditions. 1 ) Diesel can get adequate supply in Xiachuan Island.2) Distributed wind power generation can be completely consumed by the energy storage system and cable and under local load.3) The system simulation period is 25 years.4) The cost of fan and PV includes the cost of auxiliary equipment such as converter.5) Line loss is not taken into account.

\subsection{Simulation analysis}

According to the basic configuration of the first phase of the intelligent microgrid, the micro grid configuration model is set up in HOMER software, the number of wind power equipment running, and the selection range of distributed generation type are also set up. By inputting the above data, the simulation model can be built in the main interface of HOMER, as shown in Fig. 6.

In the Homer software platform, based on the model of Fig. 6 and the calculation model in the previous section, the simulation is carried out. 480 kinds of matching schemes are calculated, and 4 typical schemes are selected by HOMER software. In the HOMER 
simulation scheme, the optimal scheme is scheme 1, and then the second, third, fourth optimal schemes are the second, third, fourth scheme. The basic configuration, capital, power generation and emission of the four schemes are analyzed in the next section.

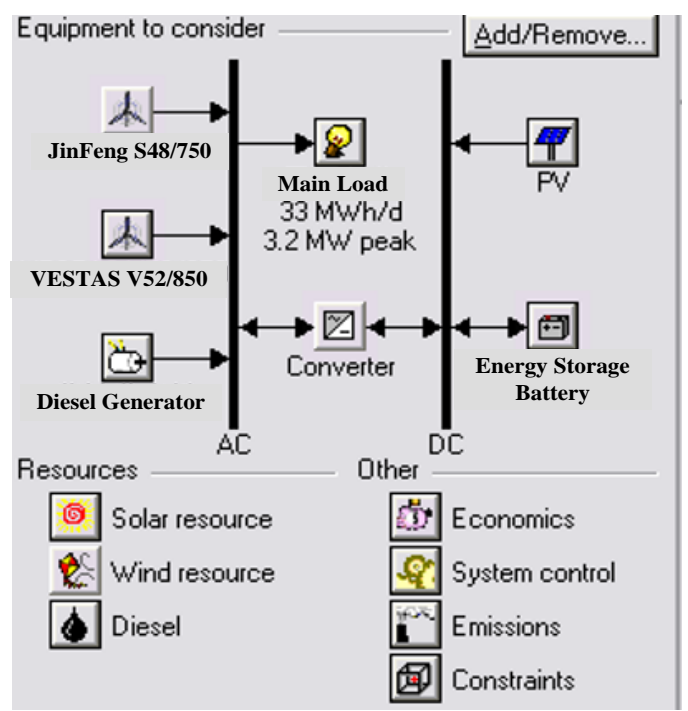

Fig. 6. Off-grid Islands micro-grid simulation model

Table 1. The system configuration comparison

\begin{tabular}{|c|c|c|c|c|}
\hline $\begin{array}{l}\text { Distributed } \\
\text { generation }\end{array}$ & $\begin{array}{c}\text { System } \\
\text { scheme } 1\end{array}$ & $\begin{array}{c}\text { System } \\
\text { scheme } 2\end{array}$ & $\begin{array}{c}\text { System } \\
\text { scheme } \\
3 \\
\end{array}$ & $\begin{array}{c}\text { System } \\
\text { scheme } \\
4 \\
\end{array}$ \\
\hline $\begin{array}{c}\text { Photovoltai } \\
\text { c } \\
\end{array}$ & $2,000 \mathrm{~kW}$ & NONE & $\begin{array}{c}3,000 \\
\mathrm{~kW}\end{array}$ & NONE \\
\hline $\begin{array}{c}\text { Diesel } \\
\text { generators }\end{array}$ & $4,000 \mathrm{~kW}$ & $4,000 \mathrm{~kW}$ & $\begin{array}{c}4,000 \mathrm{k} \\
\mathrm{W}\end{array}$ & $\begin{array}{c}4,000 \mathrm{k} \\
\mathrm{W}\end{array}$ \\
\hline $\begin{array}{c}\text { Wind } \\
\text { Power } \\
\text { generation }\end{array}$ & $\begin{array}{c}\text { 7'VESTA } \\
\mathrm{S} \\
\text { V52/850 }\end{array}$ & $\begin{array}{c}\text { 10’VEST } \\
\text { AS } \\
\text { V52/850 }\end{array}$ & NONE & NONE \\
\hline $\begin{array}{l}\text { Energy } \\
\text { storage } \\
\text { battery }\end{array}$ & $1980 \mathrm{kWh}$ & $1980 \mathrm{kWh}$ & $\begin{array}{c}1980 \mathrm{~kW} \\
\mathrm{~h}\end{array}$ & $\begin{array}{c}1800 \mathrm{~kW} \\
\mathrm{~h}\end{array}$ \\
\hline
\end{tabular}

Table 2. The system Investment cost comparison.

\begin{tabular}{|c|c|c|c|c|}
\hline $\begin{array}{c}\text { Cost } \\
\text { expendit } \\
\text { ure }\end{array}$ & $\begin{array}{c}\text { System } \\
\text { scheme 1 }\end{array}$ & $\begin{array}{c}\text { System } \\
\text { scheme 1 }\end{array}$ & $\begin{array}{c}\text { System } \\
\text { scheme 1 }\end{array}$ & $\begin{array}{c}\text { System } \\
\text { scheme 1 }\end{array}$ \\
\hline $\begin{array}{c}\text { Inverst } \\
\text { ment } \\
\text { Cost }\end{array}$ & $\begin{array}{c}¥ 471,5 \\
75,968\end{array}$ & $\begin{array}{c}¥ 486,15 \\
0,912\end{array}$ & $\begin{array}{c}Y \\
730,49\end{array}$ & $\begin{array}{c}¥ \\
491,06 \\
4,960\end{array}$ \\
\hline $\begin{array}{c}\text { Cost of } \\
\text { power } \\
\text { geenerat } \\
\text { ion }\end{array}$ & $\begin{array}{c}¥ 3.28 / \mathrm{k} \\
\mathrm{Wh}\end{array}$ & $\begin{array}{c}¥ 3.401 / \mathrm{k} \\
\mathrm{Wh}\end{array}$ & $\begin{array}{c}¥ 3.712 / \mathrm{k} \\
\mathrm{Wh}\end{array}$ & $\begin{array}{c}¥ 4135 / \mathrm{k} \\
\mathrm{Wh}\end{array}$ \\
\hline $\begin{array}{c}\text { Mainten } \\
\text { ance } \\
\text { cost }\end{array}$ & $\begin{array}{c}¥ 27,962 \\
152 / \mathrm{yr}\end{array}$ & $\begin{array}{c}¥ 31,678, \\
208 / \mathrm{yr}\end{array}$ & $\begin{array}{c}¥ 35,607, \\
416 / \mathrm{yr}\end{array}$ & $\begin{array}{c}¥ 47,833, \\
848 / \mathrm{yr}\end{array}$ \\
\hline
\end{tabular}

1) Capacity distribution comparison of microgrid distributed generation.

The system configuration comparison of the 4 schemes calculated by HOMER simulation software is shown in table 1.

2) The system Investment cost comparison

The system Investment cost comparison of the 4 schemes calculated by HOMER simulation software is shown in Table 2.

3) Comparison of emission data

The system comparison of emission data of the 4 schemes calculated by HOMER simulation software is shown in Table 3.

Table 3. Comparison of pollutants discharged

\begin{tabular}{|c|c|c|c|c|}
\hline $\begin{array}{c}\text { Contaminan } \\
\text { ts }\end{array}$ & $\begin{array}{c}\text { System } \\
\text { scheme } \\
\mathbf{1}(\mathbf{k g} / \mathbf{y r})\end{array}$ & $\begin{array}{c}\text { System } \\
\text { scheme } \\
\mathbf{2}(\mathbf{k g} / \mathbf{y r})\end{array}$ & $\begin{array}{c}\text { System } \\
\text { scheme } \\
\mathbf{3 ( k g / y r )}\end{array}$ & $\begin{array}{c}\text { System } \\
\text { scheme } \\
\mathbf{4}(\mathbf{k g} / \mathbf{y r})\end{array}$ \\
\hline $\mathbf{C O 2}$ & $\begin{array}{c}8,254,69 \\
6\end{array}$ & $\begin{array}{c}9,747,26 \\
9\end{array}$ & $\begin{array}{c}10,975,47 \\
4\end{array}$ & $\begin{array}{c}15,819,81 \\
2\end{array}$ \\
\hline $\mathbf{C O}$ & 20,378 & 24,060 & 27,091 & 39,049 \\
\hline $\begin{array}{c}\text { Hydrocarbo } \\
\mathbf{m}\end{array}$ & 2,257 & 2,665 & 3,001 & 4,325 \\
\hline PM & 1,536 & 1,814 & 2,042 & 2,944 \\
\hline SO2 & 16,577 & 19,574 & 22,041 & 31,769 \\
\hline $\begin{array}{c}\text { Nitrogen } \\
\text { and oxygen } \\
\text { compounds }\end{array}$ & 181,813 & 214,687 & 241,739 & 348,437 \\
\hline
\end{tabular}

According to HOMER simulation software calculation, it is the optimal scheme that can meet the relevant requirements of emissions, power generation, investment maintenance costs and other factors.

Based on the virtual energy pool and HOMER simulation software, the modeling and simulation of the intelligent configuration of intelligent micro grid in Xiachuan Island are carried out. The comparison results between simulation cases have certain reference value for the microgrid pluripotent complementary and comprehensive economic optimization planning, which can optimize intelligent microgrid distributed power generation networking scheme.

\section{Conclusion}

A microgrid structure model based on virtual energy pool is proposed in this paper. A comprehensive benefit planning and optimization method for microgrid is proposed, which can optimize and evaluate the economic efficiency of microgrid construction and operation. An example of economic planning for distributed energy resources of an island microgrid is given. The simulation results are analyzed in detail. It is proved that this method is objective, accurate, credible and operable. It is an effective method in microgrid planning process. This method also has a high reference value for the economic evaluation of micro grid and other aspects of smart grid.

\section{Acknowledgements}

This research is supported by the Young Backbone Teachers Project in Henan Colleges and universities, China (Project nos. 2019GGJS148), by the Department 
of Science \&Technology Fund Project of Henan Province, China (Project nos. 162102210092 and 142102210579), the Zhengzhou Administration of Science \& Technology Fund Project of Henan Province, China (Project no. 141PPTGG363), by the HaMI Administration of Science \& Technology Fund Project of Xinjian Province, China (Project no. 2017-2019), and by the Henan Province Engineering Laboratory Project of Henan Province, China (Project no. YuTi2017-119).

\section{References}

1. R. Gholami, M. Shahabi, M.-R. Haghifam. An efficient optimal capacitor allocation in DG embedded distribution networks with islanding operation capability of micro-grid using a new genetic based algorithm, International Journal of Electrical Power \& Energy Systems, October 2015, Vol. 71: pp. 335-343.

2. Jiyuan Zhang, Lei Huang, Jie Shu, Hao Wang, Jianning Ding. Energy Management of PV-dieselbattery Hybrid Power System for Island Stand-alone Micro-grid, Energy Procedia, May 2017, Vol. 105: 2201-2206.

3. Prachuab Peerapong, Bundit Limmeechokchai. Optimal electricity development by increasing solar resources in diesel-based micro grid of island society in Thailand, Energy Reports, November 2017, Vol. 3: 1-13.

4. María Belén Sosa, Erica Norma Correa, María Alicia Cantón. Urban grid forms as a strategy for reducing heat island effects in arid cities, Sustainable Cities and Society, July 2017, Vol. 32: 547-556.

5. Alessandro Pilloni, Alessandro Pisano, Elio Usai. Voltage Restoration of Islanded Microgrids via Cooperative Second-Order Sliding Mode Control*, IFAC-Papers Online, July 2017, Vol. 50(1):96379642.

6. Mohammad Hossein Amrollahi, Seyyed Mohammad Taghi Bathaee.Techno-economic optimization of hybrid photovoltaic/wind generation together with energy storage system in a stand-alone micro-grid subjected to demand response, Applied Energy, September 2017 Vol. 202:66-77.

7. Mohammad H. Moradi, Vahid Bahrami Foroutan, Mohammad Abedini. Power flow analysis in islanded Micro-Grids via modeling different operational modes of DGs: A review and a new approach, Renewable and Sustainable Energy Reviews, March 2017, Vol. 69 :248-262.

8. Jie Yang, Bo Zhao, Chong Wang, Feng Qiu, Rongfei Wang, Yu Yang. Improving the growth of $\mathrm{Ge} / \mathrm{Si}$ islands by modulating the spacing between screen and accelerator grids in ion beam sputtering deposition system, Applied Surface Science, November 2016, Vol. 386:303-308.
9. Morteza Nazari-Heris, Saeed Abapour, Behnam Mohammadi-Ivatloo. Optimal economic dispatch of FC-CHP based heat and power micro-grids, Applied Thermal Engineering, March 2017, Vol. 114: 756769.

10. Peng Zhang, Jing Chang, Boyang Qu, and Qifeng Zhao. Denoising and Trend Terms Elimination Algorithm of Accelerometer Signals, Mathematical Problems in Engineering, April 2016, Vol. 2016:1-9.

11. Yahya Koraz, A. Gabbar. "Risk analysis and selfhealing approach for resilient interconnect micro energy grids", Sustainable Cities and Society, pp. 638-653, Vol.32, July 2017.

12. Derek Chan, Mark Cameron, Younju Yoon. "Implementation of micro energy grid: A case study of a sustainable community in China", Energy and Buildings, pp. 719-731, Vol. 139, March 2017.

13. LI Deng-feng, XIE Kai-gui, HU Bo, et al. Optimal configuration of microgrid power supply based on maximizing net benefits, Power System Protection and Control, Oct. 2013, Vol. 41(20): 20-26.

14. FU Yang, JIANG Yi-liu, LI Zhen-kun. Optimal allocation of distributed generation for microgrid based on hybrid quantum genetic algorithm, Power System Protection and Control, Dec. 2013, Vol. 41(24) :50-57.

15. XU Dan, DING Qiang, PAN Yi, et al. Study on optimizing capacity of storage battery in microgrid system based on economic dispatch. Power System Protection and Control, Aug. 2011, Vol. 39(17):5559.

16. Sohrab Mirsaeidi, Dalila Mat Said, Mohd. Wazir Mustafa, Mohd. Hafiz Habibuddin, Kimia Ghaffari. Modeling and simulation of a communicationassisted digital protection scheme for micro-grids, Renewable and Sustainable Energy Reviews, May 2016, Vol. 57: 867-878.

17. Hamed Badihi, Youmin Zhang, Henry Hong. Faulttolerant cooperative control in an offshore wind farm using model-free and model-based fault detection and diagnosis approaches. Applied Energy, 1 September 2017, Vol. 201: 284-307.

18. Xiangning Lin, Rui Zhang, Ning Tong, Xianshan Li, Ming Li, Dexian Yang. Regional protection scheme designed for low-voltage micro-grids, International Journal of Electrical Power \& Energy Systems, January 2015, Vol. 64:526-535.

19. Andrew Wing Keung To, Gavin Paul, Dikai Liu. A comprehensive approach to real-time fault diagnosis during automatic grit-blasting operation by autonomous industrial robots, Robotics and Computer-Integrated Manufacturing, February 2018, Vol. 49:13-23.

20. Leo Raju, Sibi Sankar, R.S. Milton. Distributed Optimization of Solar Micro-Grid Using Multi Agent Reinforcement Learning, Procedia Computer Science Jen. 2015, Vol. 46:231-239. 